\title{
Seksuell rådgjeving etter hjarteinfarkt
}

\author{
Korleis kan helsepersonell gje råd til hjartepasientar om seksualitet og helse?
}

\section{FORFATTERE}

Alfred Absalon Rygg

Spesialsjukepleiar

Jan Mårtensson

\section{HOVEDBUDSKAP}

Mange pasientar som har hatt hjarteinfarkt, opplever seksuelle problem. Likevel får dei lite eller ingen informasjon om dette frå helsepersonell til tross for at det føreligg tilrådingar som seier at desse pasientane bør få seksuell rådgjeving, og korleis rådgjevinga skal utførast.

Seksualitet er ein viktig del av det å vere menneske. Verdas helseorganisasjon (WHO) definerer seksuell helse som ein tilstand av fysisk, psykisk, kjenslemessig og sosialt velvære når det gjeld seksualitet. Seksuell helse er ikkje berre fråvær av sjukdom, funksjonssvikt eller manglande helse $(1,2)$. Seksualitet blir påverka av sjukdom, dysfunksjon og funksjonsnedsettingar og handlar ikkje berre om seksuell aktivitet slik som samleie, men òg om nærleik, berøring, intimitet og kjærteikn.

Til tross for at seksualiteten blir påverka, kan likevel seksuelt velvære opplevast $(3,4)$. Seksuell helse handlar om livskvalitet og personlege relasjonar. I mange tilfelle overser ein dei positive funksjonane seksualitet kan ha på livskvalitet. Målet om ei god seksuell helse inneber at alle menneske skal ha like moglegheiter, rettigheiter og føresetnadar for å få bekrefta sin eigen seksualitet og bestemme over eigen kropp (5).

\section{SEKSUELL HELSE}

Frekvensen av erektil dysfunksjon hos menn og seksuell dysfunksjon hos kvinner med hjartesjukdom er dobbelt så høg som hos normalbefolkninga (6). Slik dysfunksjon kan vere tidleg teikn på hjartesjukdom som kan vise seg eitt til tre år før ei hjartehending (7). Seksuell aktivitet blir assosiert med auka risiko for å få eit hjarteinfarkt, men studiar viser at dette er årsak til berre ein prosent av alle akutte hjarteinfarkt.

Absolutt risiko for å få eit hjarteinfarkt i samband med ein time seksuell aktivitet i veka er anslått til å råke to til tre av 10000 personar i året. Personar som har hatt hjarteinfarkt tidlegare, har ikkje noko større risiko for å få eit nytt hjarteinfarkt i samband med seksuell aktivitet samanlikna med personar som ikkje har hatt koronarsjukdom tidlegare (8). 
Eit hjarteinfarkt inneber ofte store endringar i eit menneske sitt liv. Mange opplever seksuelle problem i etterkant. Både menn og kvinner har mindre seksuell aktivitet og er mindre tilfredse med den seksuelle aktiviteten etter eit hjarteinfarkt. Årsaka til dette kan vere angst og depresjon på grunn av hjarteinfarktet, redsel for å få eit nytt hjarteinfarkt eller redsel for å døy. Hjarteinfarktpasientar må ofte bruke ulike medikament som skal betre og stabilisere hjartet sin funksjon. Desse medikamenta kan gje biverknadar som påverkar seksuell funksjon $(9,10)$. Forsking viser at hjarteinfarktpasientar ynskjer meir kunnskap om situasjonen dei er i. Dei treng òg rådgjeving i samband med seksualitet, men opplever at dei ikkje får dette frå helsevesenet (11).

\section{SEKSUELL RÅDGJEVING}

Hensikta med denne artikkelen er å greie for korleis seksuell rådgjeving til pasientar som har gjennomgått eit hjarteinfarkt, blir handtert, når seksuell rådgjeving bør finne stad, kven som har ansvar for dette, kva den bør innehalde, og korleis seksuell rådgjeving bør utførast.

Seksuell rådgjeving er ein interaksjon med pasient og partnar, med informasjon om seksuelle bekymringar og sikker tilbakegang til seksuell aktivitet. I tillegg dekker rådgjevinga vurdering, støtte og konkrete råd knytte til psykiske og seksuelle problem, òg kalla psykoseksuell rådgjeving. Det er utarbeidd retningslinjer som tilrår at helsepersonell diskuterer seksualitet med hjartepasientar, men dette blir praktisert lite i det daglege.

American Heart Association (AHA) og European Society of Cardiology (ESC) har samanfatta evidens relatert til seksuell rådgjeving ved kardiovaskulær sjukdom. Dokumentet gjev rettleiing til legar, sjukepleiarar og anna helsepersonell som skal praktisere seksuell rådgjeving (13). Hjarteinfarktpasientar får lite eller ingen informasjon og støtte om seksuelle problem. Dette kan skyldast misoppfatningar hos både helsepersonell og pasient knytt til seksuell rådgjeving etter ei hjartehending $(12,13)$.

\section{TEMAET ER TABU}

Seksualitet er for mange vanskeleg å snakke om, og helsepersonell tek ikkje opp temaet fordi ein ser det å vere for intimt og privat å snakke om (9). Helsepersonell sine haldningar, oppfatningar og åtferd kan påverke kor vidt seksuell rådgjeving blir utført. Kjensla av ikkje å vere komfortabel med, eller av å vere flau for å snakke om seksualitet, blir skildra som ein stor barriere.

Andre barrierar som blir skrive om, er at helsepersonell trur at pasientane ikkje ynskjer å snakke om seksualitet, og at pasientane opplever at helsepersonellet har manglande kunnskapar til å gje seksuell rådgjeving. Det vert òg skildra barrierar relatert til institusjonen, om at det er for lita tid til seksuell rådgjeving. Personalet må prioritere å bruke tida til å ta seg av pasientar som har større pleie- og overvakingstrong. Privatlivet til pasientane som ein ynskjer å diskutere seksualitet med, blir lite ivaretatt (12-16).

\section{NÅR GJE RÅD?}

Det finnast tilrådingar som seier at rådgjeving bør finne stad medan pasienten er på sjukehus, eller etter pasienten er utskriven. Andre tilrådingar seier at rådgjevinga bør starte på sjukehus og fortsette etter at pasienten er utskriven, gjerne i eit hjarterehabiliteringsprogram $(13,15)$. I løpet av eit sjukehusopphald er fysioterapeutar ofte inne i biletet for å snakke med pasienten om kva fysisk aktivitet dei kan drive med etter eit hjarteinfarkt. Å diskutere seksuelle problem i samband med fysisk aktivitet og trening kan vere gunstig (12). Ikkje alle pasientar ynskjer å diskutere seksuelle problem, spesielt i den 
akutten fasen, og det er då viktig at ein respekterer dette.

Det er viktig å starte tidleg med seksuell rådgjeving til infarktpasientane og partnar som ynskjer dette, med oppfølging både under sjukehusopphaldet og etter utskriving for at pasienten kan oppretthalde seksuell integritet og livskvalitet. Mange pasientar opplever stor usikkerheit, og spørsmål om kva ein kan og ikkje kan gjere dukkar ofte opp når dei er komne tilbake til kvardagen og skal oppta dei daglege aktivitetane igjen i livet, inkludert seksuell aktivitet (17).

\section{KVEN HAR ANSVARET?}

Kven som har ansvaret for seksuell rådgjeving, er det ikkje noko konsensus på. I tilrådingane som AHA og ESC har kome med, blir titlane «helsepersonell» og «tilsette som arbeider med pasientar med kardiovaskulær sjukdom» brukte (13). I andre artiklar og studiar blir titlane «lege», «kardiolog», «sjukepleiar», «kardiologisk sjukepleiar» og «anna helsepersonell» nytta $(6,7,9-12,15,17-25)$.

Studiar viser at mange pasientar synast det er greitt at helsepersonell gjev seksuell rådgjeving, og at sjukepleiarar både i sjukehus og primærhelsetenesta spelar ei viktig rolle (18). Når ein skal snakke med pasientar om seksualitet, er det ein fordel at den som skal ha samtalen, er blitt kjent med pasienten og sjølv kjenner seg vel med å ha samtalen. Ettersom sjukepleiar kjem nær pasientane og har ein føresetnad for å bygge eit tillitsforhold, er det mykje som talar for at hovudansvaret for seksuell rådgjeving bør ligge hos sjukepleiar.

\section{«Mange opplever seksuelle problem i etterkant.»}

I litteraturen blir seksuell rådgjeving skildra som ein viktig del av sjukepleiepraksis (15). Det står at det i stor grad er opp til sjukepleiarar å implementere seksuell rådgjeving i den daglege praksis. Dette er ein form for helsefremjing, noko som fell naturleg for sjukepleiar å skulle meistre (11). Til tross for dette møter ein store barrierar som hindrar at pasientane får seksuell rådgjeving. Hovudbarrierane kan ein tenkje er forlegenheit blant sjukepleiarar til å diskutere seksualitet med pasientar, i kombinasjon med for lite kunnskap om seksualitet og seksuell rådgjeving. Om ein manglar fysisk rom der ein kan ta opp temaet med pasienten, er òg det ein barriere.

\section{TRENG OPPLARING}

I konsensusdokumentet til AHA og ESC (13) er det tilrådd at personell som arbeider med hjartepasientar, treng opplæring innan seksuell vurdering, kommunikasjonsteknikkar og seksuell rådgjeving. Opplæringa må ikkje berre fokusere på kunnskapar om og innhald av seksuell rådgjeving, men òg på å auke komforten hos personellet som skal utføre rådgjevinga $(13,16)$. På nokre sjukehus finnast det sexterapeutar eller sexologar som kan vere behjelpelege både for pasienten og for sjukepleiarar, men på langt nær alle sjukehus har dette tilbodet. På dei sjukehusa som har sexolog, er dette tilbodet ofte lite opplyst.

Ein kan òg diskutere om det er nok merksemd på seksualitet og seksuell rådgjeving på grunnutdanninga i sjukepleia. I ein studie frå 2013 som er gjort blant 320 sjukepleiarar som jobba på akuttavdeling eller med hjarterehabilitering, svara meir enn halvparten at det var lite eller inga merksemd på seksualitet og seksuell rådgjeving i grunnutdanninga. Dei svara òg at det berre var eit fåtal som fekk opplæring eller tok meir utdanning utover grunnutdanning innan handtering av seksualitet (19).

\section{GÅ GJENNOM MEDISINAR}

Mange hjarteinfarktpasientar ynskjer å få informasjon om seksualitet. Korleis dei kan 
gjenoppta seksuell aktivitet på ein trygg måte er ofte ei stor bekymring $(13,15)$. I

konsensusrapporten til AHA og ESC (13) blir det nytta evidensgradering og tilrådingar (figur 1). Rapporten samanfattar evidens for seksuell rådgjeving med generelle råd om seksuell aktivitet ved hjartesjukdom. Den lyftar òg fram tilrådingar som er meir diagnosespesifikke (13).

Figur 1: Gradering av evidens og anbefalingar

Evidensgrad

A. Data frå multiple randomiserte kliniske studiareller metaanalysar.

B. Data frå ein randomisert klinisk studie eller ikkje-randomiserte studiar.

C. Berre konsensusutsegn frå ekspertar, case-studiar eller standardbehandling.

Anbefalingar

Klasse $1 . \quad$ Behandlinga børbrukast.

Klasse 2A. Behandlingabør vurderast å bli brukt.

Klasse 2B. Behandlinga kan vurderast å bli brukt.

Klasse 2. Behandlinga børikkje brukast.

Anbefalingar med evidensgrad B eller C inneber ikkje at anbefalinga er svak. Mange viktige kliniske problemstillingar som vert tekne oppi rapporten er ikkje eigna for kliniske studiar (7).

Figur 1: Gradering av evidens og anbefalingar

Seksuell rådgjeving ved hjartesjukdom bør innehalde ein gjennomgang av medikamenta til pasienten, med informasjon om korleis desse kan påverke seksuell funksjon og om at det er viktig at pasienten rapporterer dersom det oppstår biverknader. Det hender at pasientar sluttar å ta medisinar på grunn av biverknader. Difor er det viktig å snakke om kva risiko det inneber, og at ei lita dosejustering kan vere nok til at biverknadane forsvinn. Eventuelt kan ein bytte til eit anna medikament med same effekt, dersom det ikkje aukar risikoen for komplikasjonar (KI. 2A;C).

Kardiovaskulær sjukdom i seg sjølv kan føre til seksuell dysfunksjon, så det er viktig å kartlegge om det er sjukdomen eller biverknader frå medikamenta som fører til problem. Det kan vere ein fordel å oppmuntre til å bruke kjente og komfortable stillingar for å redusere stress i samband med seksuell aktivitet (KI. $2 \mathrm{~A} ; \mathrm{C})$. Det kan òg vere ein fordel å bruke aktivitetar som kyssing, kosing og kjærteikn som ein overgang til samleie eller for dei som ikkje klarer å utføre samleie på grunn av redusert hjartekapasitet, då dei krev mindre energiforbruk (KI. 2A;B). Kardiovaskulære symptom i løpet av seksuell aktivitet førekjem sjeldan hos pasientar som ikkje har opplevd liknande symptom ved trening.

\section{NÅR GJENOPPTA SEX?}

Det er rimeleg å oppmuntre pasienten til å gjenoppta seksuell aktivitet når pasienten er $\mathrm{i}$ stand til å belaste 3-5 METs. Metabolsk ekvivalent (MET) er eit fysiologisk mål på energiforbruk for fysisk aktivitet. Ein MET-skår på 1 gjev eit oksygenforbruk på 3,5 ml oksygen per kilo per minutt, medan 2 METs gjev ei dobling av oksygenforbruket. Ein MET-skår på 3 gjev tre gongar så høgt oksygenforbruk som ved $1 \operatorname{MET}(13,20,26)$.

Seksuell aktivitet blir ofte likestilt med 2-3 METs i preorgasmisk fase, og 3-4 METs under orgasme, som svarar til å gå 5-6 km/time på eit plant underlag (6). Regelmessig fysisk trening er assosiert med redusert risiko for at seksuell aktivitet skal trigge kardiovaskulære hendingar. Difor kan det vere gunstig å inkludere tilrådingar om fysisk trening som ein del av seksuell rådgjeving (KI. 2A;B). 
Informasjon om risiko knytt til seksuell aktivitet bør vere ein del av rådgjevinga. Pasientar med låg risiko bør oppmuntrast til å starte eller gjenoppta seksuell aktivitet. Dei med høg risiko eller dei som opplever kardiovaskulære symptom ved seksuell aktivitet, bør vente til sjukdomstilstanden har stabilisert seg (KI. 2A;B). Pasientar må oppfordrast til å rapportere alle symptom dei opplever i samband med seksuell aktivitet. Nitroglyserin kan nyttast dersom det oppstår brystsmerter ved seksuell aktivitet. Dersom smertene ikkje går over, oppfordrast det til å søke medisinsk hjelp (KI. 1;B) $(13,20)$.

\section{START MED KYSS OG KOS}

Pasientar som har gjennomgått eit ukomplisert hjarteinfarkt, der sjukdomstilstanden har stabilisert seg og dei er asymptomatiske ved mild til moderat aktivitet, tilrådast å gjenoppta seksuell aktivitet etter ei veke eller meir etter hjartehendinga. Dei bør starte gradvis med aktivitetar som krev mindre anstrenging, som kyssing, kosing og kjærteikn, som ein overgang til samleie. Dette kan vere med på å bygge tillit mellom pasienten og partnar. I tillegg får dei testa ut på ein forsiktig måte kva den som har gjennomgått hjarteinfarktet, toler med tanke på seksuell aktivitet (KI. 2A;C).

Det er òg viktig å gje pasientane informasjon om at dersom det ikkje oppstår anginasmerter under trening, så er det liten risiko for at dette skal oppstå under seksuell aktivitet. Dersom anginasmerter likevel skulle oppstå, og smertene ikkje går over av seg sjølv innan eit kvarter eller fem minuttar etter å ha teke nitroglyserin, er det tilrådd at pasienten tek kontakt med legevakta (KI. 2B;C). For pasientar som brukar PDE5-hemmarar før seksuell aktivitet, er det tilrådd at dei ikkje bruker nitrat ved anginasmerter, då kombinasjonen av desse preparata kan gje blodtrykksfall. Pasienten må då oppfordrast til å ta kontakt med legevakt eller nødtelefon (KI. 3;C) $(13,20)$.

\section{KORLEIS GJE RÅD?}

Det er utvikla fleire ulike modellar som skal vere til hjelp ved seksuell rådgjeving. PLISSIT-modellen, utvikla av sexolog Jack Annon i 1975, er det vanlegaste verktøyet helsepersonell brukar for å gje seksuell rådgjeving til pasient og partnar. PLISSIT står for Permission, Limited Information, Specific Suggestion og Intensive Therapy. Dei to første trinna i denne modellen er enkle trinn å bruke som verktøy når ein skal gje seksuell rådgjeving.

Ein startar med å be pasienten om løyve til å ta opp seksuelle tema for å avklare grad av hjelpetrong, skape tryggleik rundt seksualitet og signalisere at det er ein viktig del av livet til mange menneske. Deretter gjev ein pasienten ei avgrensa mengde informasjon om seksualitet, slik at pasienten får svar på bekymringar og utfordringar. Det kan vere hensiktsmessig å bruke ein gradvis tilnærmingsmåte der ein inkluderer erfaringar frå andre pasientar eller brukar evidensbasert kunnskap for å opne samtalen.

Spørsmålet «Det er vanleg at den seksuelle helsa blir påverka av eit hjarteinfarkt, er dette noko du ynskjer å snakke om?» er eksempel på gradvis tilnærming. På denne måten opnar sjukepleiar opp for at det er greitt å snakke om seksualitet. Ein gjev pasienten tryggleik på at seksuelle problem er noko fleire opplever etter eit hjarteinfarkt, men at det blir på pasienten sine vilkår.

\section{«Eit hjarteinfarkt inneber ofte store endringar i eit menneske sitt liv.»}

Tredje trinnet i modellen, spesifikk rådgjeving, inneber at ein må tilpasse informasjon om seksualitet. Denne delen krev kunnskapar og ekspertise som er relevant for den aktuelle 
pasienten og partner med eit spesifikt problem eller tilstand. Det er hensiktsmessig at rådgjeving på dette trinnet vert utført av sjukepleiar eller lege med spesialisering, eller med mykje kunnskapar og erfaring innan temaet.

Siste trinnet, intensiv terapi, går ut på å behandle alvorlege seksuelle problem. Slik terapi krev spesialkompetanse og utdanning innan sexologi $(3,13,21)$. ALARM, BETTER og PLEASURE er døme på andre modellar som skal vere til hjelp for å vurdere pasienten si seksuelle helse, og som kombinerer vurdering og intervensjon (3).

\section{INFORMER I GRUPPER}

Når sjukepleiar skal gje seksuell rådgjeving til pasient og partnar, kan ein nytte informasjonsbrosjyrar og anna trykt materiale som er utarbeidd på bakgrunn av tidlegare pasientar og partnare sine erfaringar, med spørsmål og svar om seksualitet og samliv. Implementering av gruppeundervisning for pasient og partnar kan vere ein gunstig metode for seksuell rådgjeving (18).

Gruppeundervisning eller praktisering av seksuell rådgjeving i ein klasserommodell kan vere med på å gjere sjukepleiaren meir komfortabel ved at det blir som ei undervisning og ikkje som ein-til-ein-rådgjeving (15). Dette kan vere med på å hindre at barrierar som beskrive tidlegare, skal oppstå (18). Ein må òg ha i tankane at gruppeundervisning ikkje passar for alle pasientar, då mange har vanskar med å diskutere si seksuelle helse med sin partnar. Då er det eit stort og uhandterleg steg for mange å skulle diskutere dette i grupper.

\section{OPPSUMMERING}

Det føreligg tilrådingar om kva informasjon pasientar med hjartesjukdom bør få og korleis sjukepleiarar og anna helsepersonell kan gå til verks for å drive med seksuell rådgjeving. Seksuell helse og rådgjeving bør få meir merksemd allereie på grunnutdanningsnivå innan sjukepleiefaget. Der bør òg vere ei auka merksemd på å kvalifisere og heve kunnskapen til allereie utdanna sjukepleiarar og anna helsepersonell. Helsepersonell, då særleg sjukepleiarar, som arbeidar med hjarteinfarktpasienter og pasientar med anna hjartesjukdom, må ta eit aktivt ansvar for å diskutere seksualitet med pasientane. Dei kan med fordel ta i bruk informasjons- og undervisningsmateriale og hjelpemiddel som allereie finnast.

\section{REFERANSAR}

1. WHO. Defining sexual health. Report of a technical consultation on sexual health 28-3101.2002, Geneve. 2002.

2. Kunnskapssenteret. Effekter av seksualterapeutiske intervensjoner for seksuelle problemer. Rapport nr. 2-2012. Oslo: Nasjonalt kunnskapssenter for helsetjenesten. 2012.

3. Sundbeck, M. Sexuell hälsa i vården: en metodbok för sjuksköterskor. Lund: Studentlitteratur. 2013.

4. Idehen M. Seksualitet og livskvalitet. København: Idehen og Munksgaard. 2013.

5. Statens folkhälsoinstitut. Sex, hälsa och välbefinnande. Östersund. 01.2012.

6. Sauer WH, Kimmel SE, Kaski JC, Saperia GM (29.01.16). Sexual activity in patients with cardiovascular disease Tilgjengelig fra: https://www.uptodate.com/contents/sexual-activity-in-patients-with-cardiovascular-disease . (Nedlastet 14.11.2016).

7. Mårtensson J, Fridlund B, Jaarsma T. Sexrådgivning viktig vid kardiovaskulär sjukdom. 
8. Levine GN, Steinke EE, Bakaeen FG, Bozkurt B, Cheitlin MD, Conti JB, Foster E et.al. Sexual activity and cardiovascular disease: A scientific statement from the American Heart Association. Circulation 2012;125:1058-72.

9. Bispo GS, de Lima Lopes J, de Barros ALBL. Cardiovascular changes resulting from sexual activity and sexual dysfunction after myocardial infarction: integrative review. J Clin Nurs 2013;22:3522-31.

10. Flàvia dos Santos A, Vera LRM. Sexuality of postinfarction patients: diagnosis, results and nursing intervention. J Clin Nurs 2013;23:2101-09.

11. Mosack V, Steinke EE. Trends in sexual concerns after myocardial infarction. J Cardiovasc Nurs 2009;24:162-70.

12. Jaarsma T, Strömberg A, Fridlund B, De Geest $S$, Mårtensson J, Moons $P$, Norekval TM, Smith K, Steinke E, Thompson DR. Sexual counselling of cardiac patients: Nurses' perception of practice, responsibility and confidence. Eur J Cardiovasc Nurs 2010;9:24-9.

13. Steinke EE, Jaarsma T, Barnason SA, Byrne M, Doherty S, Dougherty $C M$, Fridlund B, Kautz DD, Mårtensson J, Mosack V, Moser DK. Sexual counseling for individuals with cardiovascular disease and their partners: A consensus document from the American Heart Association and the ESC Council on Cardiovascular Nursing and Allied Professions. Circulation 2013;128:2075-96.

14. Steinke EE, Mosack V, Barnason S, Wright DW. Progress in sexual counseling by cardiac nurses, 1994 to 2009. Heart Lung 2011;40:15-24.

15. Crumlish B. Sexual counselling by cardiac nurses for patients following an MI. Br J Nurs 2004;13:710-13.

16. Alwani N, Jewani E, Momin S, Naveed A. Trends/issues faced by health care professionals while discussing sexual issues with patients. I-manager's J Nurs 2011;1:11-15.

17. Vassiliadou A, Stamatopoulou E, Gerodimou E, Toulia G, Pistolas D. The role of nurses in the sexual counseling of patients after myocardial infarction. Health Sci J 2008;2:111-8.

18. Ivarsson B, Fridlund B, Sjöberg T. Information from health care professionals about sexual function and coexistence after myocardial infarction: A Swedish national survey. Heart Lung 2009;38:330-5.

19. Barnason S, Steinke EE, Mosack V. Exploring nurses' perceptions of providing sexual health counseling for patients with cardiac disease: Implications for evidence-based interventions. Dimens Crit Care Nurs 2013;32:191-98.

20. Steinke EE, Jaarsma T. Sexual counseling and cardiovascular disease: practical approaches. Asian J Androl 2015;17:32-9.

21. Jaarsma T, Steinke EE, Gianotten WL. Sexual problems in cardiac patients - How to assess, when to refer. J Cardiovasc Nurs 2010;25:159-64.

22. Søderberg LH, Johansen PP, Herning M, Berg SK. Womens' experiences of sexual health 
after first-time myocardial infarction. J Clin Nurs 2013;22:3532-40.

23. Steinke EE, Barnason S, Mosack V. Changes in myocardial infarction - Specific sexual counseling by cardiac nurses. Dimens Crit Care Nurs 2011;30:331-8.

24. Brännström M, Kristofferzon ML, Ivarsson B, Nilsson UG, Svedberg P, Thylèn I, SAMMI-study group. Sexual knowledge in patients with a myocardial infarction and their partners. J Cardiovasc Nurs 2014;24:332-9.

25. Akdolun N, Terakye G. Sexual problems before and after myocardial infarction: Patients' needs for information. Rehabil Nurs 2001;26:152-8.

26. Jette M, Sidney K, Blümchen G. Metabolic equivalents (METS) in exercise testing, exercise prescription and evaluation of functional capacity. Clin Cardiol 1999;13:555-65. 